\title{
Effect of Multiple Substitutions (Pb, Ti, Zr) on Structural, Permittivity and Electrical Properties of $\mathrm{BiFeO}_{3}$ Ceramics SamitaPattanayak ${ }^{1 *}$, Niranjan Panda ${ }^{2}$, R N P Choudhary ${ }^{1}$, Ashok Kumar ${ }^{3}$ \\ 1Department of Physics, Siksha 'O' Anusandhan University, Bhubaneswar, 751030, India ${ }^{2}$ Department of Physics, Driems Engineering College, Cuttack \\ ${ }^{3}$ National Physical Laboratory (CSIR), Dr. K. S. Krishnan Road, New Delhi-110012, India \\ E-mail: samitaphy@gmail.com
}

\section{Abstract:}

Three complex polycrystalline samples of $\mathrm{Bi}_{1-x} \mathrm{~Pb}_{x} \mathrm{Fe}_{1-x} \mathrm{Zr}_{x-y} \mathrm{Ti}_{y} \mathrm{O}_{3}$, with the combination of (i) $\mathrm{x}, \mathrm{y}=0.0$ (BFO), (ii) $\mathrm{x}=$ 0.5 and $y=0.5$ (BFPTO)and (iii) $x=0.5$ and $y=0.25$ (BFPZTO) were prepared by a standard mixed oxide (solid state reaction route) method at optimized calcinations $\left(900^{\circ} \mathrm{C}\right)$ and sintering $\left(930-950^{\circ} \mathrm{C}\right)$ temperatures. The effect of multiple ( $\mathrm{Pb}, \mathrm{Ti}$ and/or $\mathrm{Zr}$ ) substitutions of different amount onthe permittivity, impedance and modulus characteristics of the materials has been investigated at different frequencies and temperature.Limitation associated with $\mathrm{BiFeO}_{3}$ (BFO) due to its semiconducting behavior acts as constraint in polling the material at room temperature leading to large dielectric loss. Attempts were made to minimizethe loss by substitution of $\mathrm{Pb}$ on the $\mathrm{Bi}$ site and $\mathrm{Ti}$ and/or $\mathrm{Zr}$ at the Fe site of BFO. The study indicates that the phase transition temperature of BFO is lowered,the degree of diffuse phase transition is enhanced and electrical parameters (dielectric constant, electrical resistivity, remnant polarization and maximum polarization) areincreased with a significant reduction in dielectric loss as a consequence of the substitution. Detailed studies of Nyquist plots with impedance and electric modulus data suggest that the existence of non-Debye type of relaxation phenomena in the materials. The ac conductivity study reveals that the conduction mechanism in the material obeys universal Jonscher's power law.

[Keywords: Multiferroic; XRD; Electrical properties; Conductivity mechanism]

\section{INTRODUCTION}

Though a large number of ferroelectric oxides are available, some perovskite oxides of a general formula, $\mathrm{ABO}_{3}\left(\mathrm{a}=\right.$ =mono-divalent and $\mathrm{B}=$ tri-hexavalent ions) such as $\mathrm{BaTiO}_{3}, \mathrm{PbTiO}_{3}, \mathrm{~Pb}(\mathrm{ZrTi}) \mathrm{O}_{3}$ (PZT)etc. exhibit high dielectric constant(permittivity), spontaneous polarization, piezoelectric coefficient, pyroelectric current, transition temperature above room temperature, etcwhich enhance their potentiality for technological applications. These unique properties are resulted from their crystal structures that affectthe domain wall formation and orientation under external stimulation.Attempts have been made to develop new materials with unique and improved properties by substitutingsuitable element(s) at the A or/ B site (s) or combining different perovskites in suitable proportions[14].Among the perovskites, $\mathrm{BiFeO}_{3}(\mathrm{BFO})$ is considered as a unique material which goes to various structural phase transitions [5]. Literature survey indicates that bismuth ferrite has ferroelectric ordering due to its distorted perovskite structure below the critical temperature $\left(T_{C} \approx 850^{\circ} \mathrm{C}\right)[6]$ and anti-ferromagnetic ordering with a cycloidal canted spin arrangement up to Neel temperature $\left(\mathrm{T}_{\mathrm{C}} \approx 370^{\circ} \mathrm{C}-380^{\circ} \mathrm{C}\right)$ [7]. Due to its semiconducting behavior, and high leakage current generated due to defects, it is difficult to pole the material by applying electric field at room temperature to get the proper ferroelectric hysteresis loop [8]. Other than the above processes,leakage problem can be reduced by working at low temperature. It has been reported that the conductivity of the material is less and the hysteresis loop of the material shows a saturation polarization of $3.5 \mu \mathrm{C} / \mathrm{cm}^{2}$ [9]. Both $\mathrm{PbTiO}_{3}$ and PZT are associated with lead 
vacancies due to evaporation of $\mathrm{Pb}$ during the processing, which leads to the increase in acceptor levels in the crystal, therefore, the conductivity problem and dielectric loss of BFO can be reduced significantly by substituting different elements ( $\mathrm{Pb}, \mathrm{Ti}, \mathrm{Zr}$ ) of PZT into A/B-sites of BFO in suitable proportions[10-13].

In the present work, attempts have been made to solve the conductivity or leakage problem of bismuth ferrite by $\mathrm{Pb}$ substitution at its $\mathrm{Bi}$ site and $\mathrm{Ti}$ and/or $\mathrm{Zr}$ substitution at the Fe site. The effect of multiple substitution on the structural, dielectric and electrical properties of the material (BFO) at high temperatures in a wide frequency range $(1 \mathrm{kHz}-1 \mathrm{MHz})$ is reported here.

\section{EXPERIMENTAL PROCEDURE}

\subsection{Materials}

The high-temperature mixed-oxide method was used to fabricate the polycrystalline sample of $\mathrm{Bi}_{1-x} \mathrm{~Pb}_{\mathrm{x}} \mathrm{Fe}_{1-\mathrm{x}}\left(\mathrm{Zr}_{\mathrm{x}-}\right.$ $y \mathrm{Ti}_{\mathrm{y}} \mathrm{O}_{3}$ (with the combination of (i) $\mathrm{x}=0.0$ and $\mathrm{y}=0.0$, (ii) $\mathrm{x}=0.5$ and $y=0.5$ and (iii) $\mathrm{x}=0.5 \& \mathrm{y}=0.25$ ). The highpurity (AR grade) ingredients; $\mathrm{Bi}_{2} \mathrm{O}_{3}$ (FINAR-extra-pure99\%), and $\mathrm{Fe}_{2} \mathrm{O}_{3}, \mathrm{PbO}, \mathrm{TiO}_{2}, \mathrm{ZrO}_{2}$ (all are from LOBA CHEME-99.9\%) were used as starting materials.

\subsection{Synthesis of materials}

These ingredients weremixed in stoichiometric proportion, and grinded to fine powder with the help of agate mortar and pestle for $2 \mathrm{~h}$ in dry (air)and as well as wet atmosphere (methanol) for $2 \mathrm{~h}$ to obtain a homogeneous mixture. The homogeneously mixed powders of each sample are calcinated separately at an optimized temperature of $900^{\circ} \mathrm{C}$ for 5 h using pure alumina crucible.

\subsection{Characterization}

The formation of pure phase compounds and the basic crystal structure of the samples were analyzed by powder Xray diffraction (XRD) method using a power diffractometer (Rigaku Mini-flex, Japan). The CuKa radiation of wavelength $(\lambda)=1.5405 \AA$ was used to record the XRD patterns and data in a wide range of Bragg angle $2 \theta$ such that $20^{\circ} \leq 2 \theta \leq 80^{\circ}$ at a scanning rate of $3^{\circ} / \mathrm{min}$ at room temperature. After confirmation of the compound formation, the calcinated powders of different samples were separately cold pressed into small circular pellets of approximate diameter $10 \mathrm{~mm}$ and thickness $1-2 \mathrm{~mm}$ at pressure of $4 \times 10^{6} \mathrm{~N} / \mathrm{m}^{2}$ using uniaxial hydraulic press. The polyvinyl alcohol (PVA) was used as the binder to form pellets. The pellets are sintered at optimized temperature of $930^{\circ} \mathrm{C}-950^{\circ} \mathrm{C}$ for $4 \mathrm{~h}$. The microstructure of the sintered pellets was recorded by using scanning electron microscope (SEM-JEOL-JSM, model 6510) at a magnification of 6000. The parallel surfaces of circular pellets of each sample were polished and electroded by using air drying silver paint for electrical measurements. Before taking the electrical measurements, the pellets were dried at temperature $150^{\circ} \mathrm{C}$ for $3 \mathrm{~h}$ and then cooled at room temperature. The electrical parameters such as phase, dielectric loss, impedance, parallel L, parallel $\mathrm{C}$, parallel $\mathrm{R}$ of the materials were measured as a function of frequency $(1 \mathrm{kHz}-1 \mathrm{MHz})$ and temperature $\left(25^{\circ} \mathrm{C}-500^{\circ} \mathrm{C}\right)$ using a phase sensitive LCR/Impedance meter (PSM. 1735, N4L). The ferroelectric hysteresis loop of each sample was traced at room temperature by using a $\mathrm{P}-\mathrm{E}$ loop tracer (M/S Radiant Technologies Inc., USA), after proper polling of the pellet of each compound.

\section{RESULTS AND DISCUSSION}

\subsection{Structural Analyses}


The room temperature XRD patterns of $\mathrm{Bi}_{1-\mathrm{x}} \mathrm{Pb}_{\mathrm{x}} \mathrm{Fe}_{1-\mathrm{x}}\left(\mathrm{Zr}_{\mathrm{x}-\mathrm{y}} \mathrm{Ti}_{\mathrm{y}}\right) \mathrm{O}_{3}$, with(i) $\mathrm{x}=0.0$ \& $\mathrm{y}=0.0$ (ii) $\mathrm{x}=0.5$ \& $\mathrm{y}=0.5$ (iii) $\mathrm{x}=$ $0.5 \& y=0.25$ are compared in Figure 1.All the peaks of the XRD patterns were indexed in tetragonal system using standard computer software POWDMULT [14] and the lattice parameters of the samples were obtained.

The difference between the observed (obs) and calculated value (cal) of inter planner distance $d\left[\sum\left(d_{\text {obs }}-d_{c a l}\right)=\right.$ minimum] was found to be minimum in tetragonal crystal system (with space group $\mathrm{P} 4 \mathrm{~mm}$ ) for the $\mathrm{Pb}$ and $\mathrm{Ti}$ and/or $\mathrm{Zr}$ modified BFO whereas it was rhombohedral (R3c space group) for pure BFO [15-18]. The strongest diffraction peak was found at (110) plane for all the compounds. It is also found that in the $\mathrm{Pb}$ and $\mathrm{Ti}$ doped $\mathrm{BiFeO}_{3} \mathrm{compound}_{\text {, }}$ the diffraction peaks shifts towards the higher angle while $\mathrm{Zr}$ added compound the diffraction peaks shifts towards the lower angle. Due to the larger ionic radius of $\mathrm{Pb}^{2+}(1.33 \AA)$ than that of $\mathrm{Bi}^{3+}\left(1.17 \mathrm{~A}^{\circ}\right)$ and larger ionic radius of $\mathrm{Zr}^{4+}(0.72 \AA)$ and $\mathrm{Ti}^{4+}(0.741 \AA)$ than that of $\mathrm{Fe}^{3+}(0.69 \AA)$, the volume of unit cell was larger as compared to that of pure $\mathrm{BiFeO}_{3}$. Table1 shows the comparison of tolerance factor (t) and lattice parameters of the $\mathrm{Bi}_{1-x} \mathrm{~Pb}_{x} \mathrm{Fe}_{1-x}\left(\mathrm{Zr}_{x-}\right.$ y $\left.\mathrm{Ti}_{\mathrm{y}}\right) \mathrm{O}_{3}$ samples.

Table-1: Comparison of unit cell parameters $(a, c)$, unit cell volume and tolerance factor $(t)$ of $B i_{1}$. ${ }_{x} \mathrm{~Pb}_{\mathrm{x}} \mathrm{Fe}_{1-\mathrm{x}}\left(\mathrm{Zr}_{\mathrm{x}-\mathrm{y}} \mathrm{Ti}_{\mathrm{y}}\right) \mathrm{O}_{3}$ ceramic compounds. The estimated standard deviation of unit cell data is shown within the parenthesis.

\begin{tabular}{|c|c|c|c|c|c|c|}
\hline $\mathrm{x}$ & $\mathrm{y}$ & $\mathrm{a}\left(\mathrm{A}^{\circ}\right)$ & $\mathrm{c}\left(\mathrm{A}^{\circ}\right)$ & $\mathrm{c} / \mathrm{a}$ & $\begin{array}{c}\text { Volume } \\
\left(\mathrm{A}^{\circ}\right)^{3}\end{array}$ & $\begin{array}{l}\text { Tolerance } \\
\text { factor }(\mathrm{t})\end{array}$ \\
\hline 0.0 & 0.0 & $5.5706(7)$ & $13.8114(4)$ & 2.4793 & 372.96 & 0.871 \\
\hline 0.5 & 0.5 & $5.5984(11)$ & $13.9583(7)$ & 2.4933 & 437.48 & 0.887 \\
\hline 0.5 & 0.25 & $5.6968(7)$ & $13.7963(9)$ & 2.4218 & 447.74 & 0.890 \\
\hline
\end{tabular}

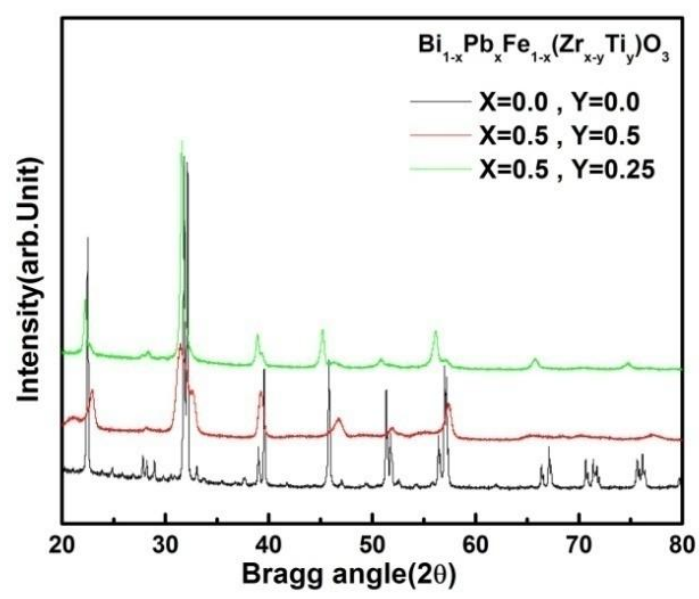

Figure 1: Comparison of XRD patterns of $\mathrm{Bi}_{1}$. ${ }_{x} \mathrm{~Pb}_{\mathrm{x}} \mathrm{Fe}_{1-\mathrm{x}}\left(\mathrm{Zr}_{\mathrm{x}-\mathrm{y}} \mathrm{Ti}_{\mathrm{y}}\right) \mathrm{O}_{3}$ compounds at room temperature
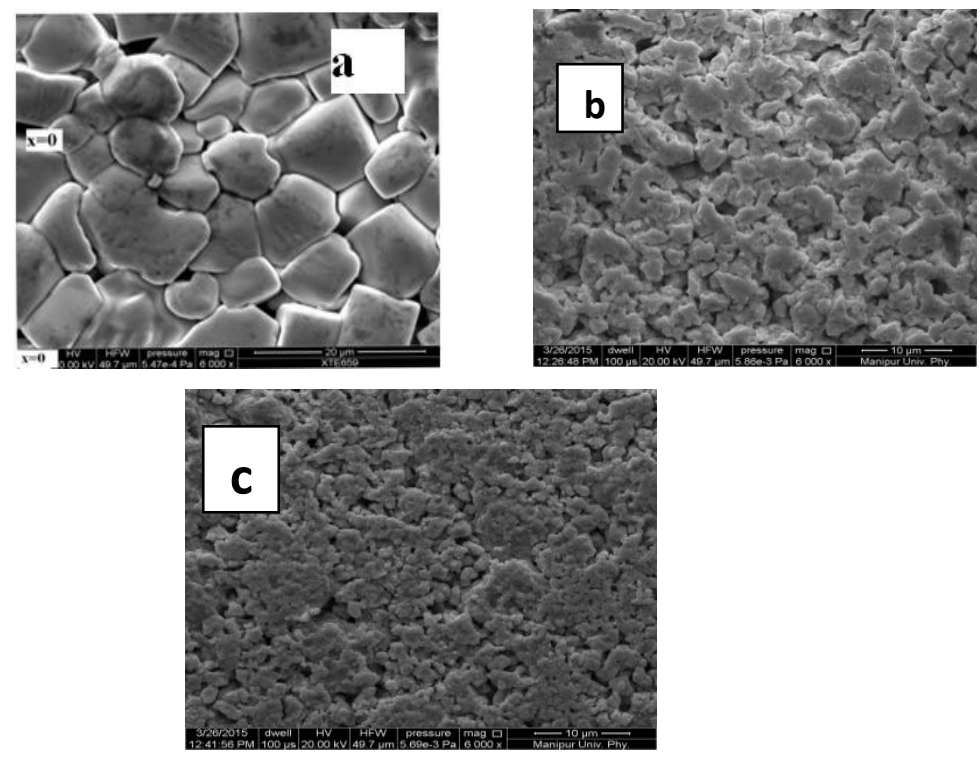

Figure 2: Scanning Electron Micrographs of $\mathrm{Bi}_{1}$ ${ }_{x} \mathrm{~Pb}_{\mathrm{x}} \mathrm{Fe}_{1-\mathrm{x}}\left(\mathrm{Zr}_{\mathrm{x}-\mathrm{y}} \mathrm{Ti}_{\mathrm{y}}\right) \mathrm{O}_{3}$ compounds (a) For BFO (b) For BFPTO and (c) For BFPZ 
It is clearly observed that the tolerance factor of BFPTO and BFPZTO compounds is larger than that of pure BFO and is more for $\mathrm{Zr}$ doped compound. This indicates that the structural stability of compounds increases due to substitution (i.e., distortion in the perovskite structure of pure BFO increases due to substitution [19]). As in all samples, $\mathrm{t}<1$, the $\mathrm{A}-\mathrm{O}$ bond length is smaller than the $\mathrm{B}-\mathrm{O}$ bond length, hence end members of $\mathrm{Bi}_{1-\mathrm{x}} \mathrm{Pb}_{\mathrm{x}} \mathrm{Fe}_{1-\mathrm{x}}\left(\mathrm{Zr}_{\mathrm{x}-\mathrm{y}} \mathrm{Ti}_{\mathrm{y}}\right)$ $\mathrm{O}_{3}$ influence more the dielectric and electric properties of the compounds [20]. The scanning electron micrograph of $\mathrm{Bi}_{1-\mathrm{x}} \mathrm{Pb}_{\mathrm{x}} \mathrm{Fe}_{1-\mathrm{x}}\left(\mathrm{Zr}_{\mathrm{x}-\mathrm{y}} \mathrm{Ti}_{\mathrm{y}}\right) \mathrm{O}_{3}$ pellets are compared in Figure-2(a, b, c). It is observed that the grain size decreases with substitution. The grains are uniformly distributed, andare very closely packed, hence porosity of BFO is reduced (i.e., density increases due to doping).

\subsection{Dielectric and Ferroelectric Properties:}

Figures ( 3 and 4) show the variation of dielectric constant $\left(\varepsilon_{r}\right)$ and dielectric loss (tanס) of $\mathrm{Bi}_{-\mathrm{x}} \mathrm{Pb}_{\mathrm{x}} \mathrm{Fe}_{1-\mathrm{x}}\left(\mathrm{Zr}_{\mathrm{x}-\mathrm{y}} \mathrm{Ti}_{\mathrm{y}}\right) \mathrm{O}_{3}$ compounds with frequency of the applied alternating electric field.. The larger dispersion observed in the dielectric constant $\left(\varepsilon_{r}\right) \sim$ frequency graph at lower frequencies indicates that the contribution of space charge polarization to the dielectric constant of BFPZTO compound is significantly large than that in BFPTO and BFO. The space charge polarization in the material is enhanced effectively by the substitution of $\mathrm{Pb}$ at the Bi-site and $\mathrm{Ti} / \mathrm{Zr}$ at the Fe-site of BFO. In all the compounds, the value of $\varepsilon_{r}$ decreases with increase in frequency at the selected temperature, and almost become frequency independent at higher frequencies (which is clearly observed in $\mathrm{Zr}$ doped compound) in the observed frequency range, which reflects the dielectric nature of the materials [14]. However, at all the frequencies the dielectric constant of BFPZTO and BFPTO compounds is larger than that of pure BFO.This indicates that the polarization stability increases with $\mathrm{Pb}, \mathrm{Ti}$ and/or $\mathrm{Zr}$ substitution. This may be due to decrease in the grain size when BFO is modified.

Figure 4shows the variation of dielectric loss of $\mathrm{Bi}_{1-x} \mathrm{~Pb}_{x} \mathrm{Fe}_{1-\mathrm{x}}\left(\mathrm{Zr}_{\mathrm{x}-\mathrm{y}} \mathrm{Ti}_{\mathrm{y}}\right) \mathrm{O}_{3}$ with frequency. It is seen that loss decreases with increase in frequency. The dispersion is large at low frequency and gradually decreases with increase in frequency, thus the tan $\delta$ value become almost frequency independent at higher frequency. It is observed that the $\mathrm{Zr}$ and/or Ti substitution reduces the dielectric loss or leakage current of BFO effectively. This fact may be due to the decrease in the $\mathrm{Fe}$ ion concentration, which is expected to cause large leakage current in BFO. Hence, the conductivity of BFPZTO and BFPTO is less than that of BFO [15].

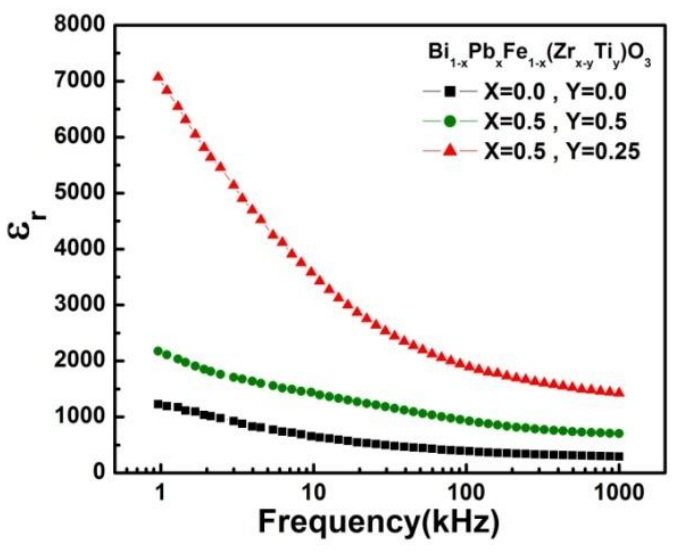

Figure 3: Variation of dielectric constant $\left(\varepsilon_{r}\right)$ of ${ }_{x} \mathrm{~Pb}_{\mathrm{x}} \mathrm{Fe}_{1-\mathrm{x}}\left(\mathrm{Zr}_{\mathrm{x}-\mathrm{y}} \mathrm{Ti}_{\mathrm{y}}\right) \mathrm{O}_{3}$ compounds with Frequency at selected temperature $300^{\circ} \mathrm{C}$

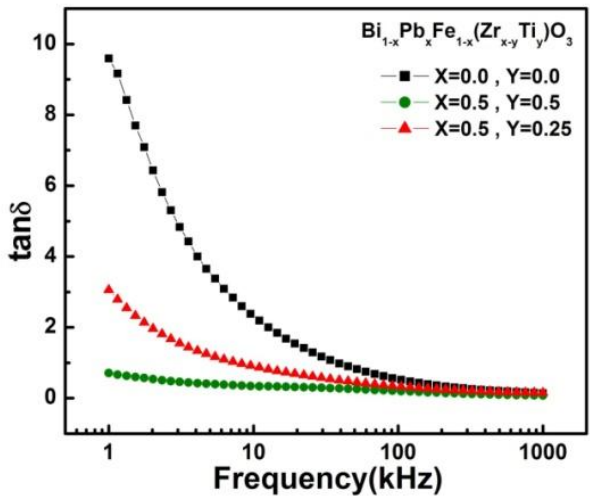

Figure 4: Variation of dielectric loss $(\tan \delta)$ of $\mathrm{Bi}_{1}$ $\mathrm{Bi}_{1-\mathrm{x}} \mathrm{Pb}_{\mathrm{x}} \mathrm{Fe}_{1-\mathrm{x}}\left(\mathrm{Zr}_{\mathrm{x}-\mathrm{y}} \mathrm{Ti}_{\mathrm{y}}\right) \mathrm{O}_{3}$ compounds with Frequency at temperature $300^{\circ} \mathrm{C}$ 
Figures5 (a-c) and 6 (a-c) exhibit the variation of dielectric constant $\left(\varepsilon_{r}\right)$ and dielectric loss $(\tan \delta)$ of $\mathrm{Bi}_{1-x} \mathrm{~Pb}_{x} \mathrm{Fe}_{1}$ ${ }_{x}\left(\mathrm{Zr}_{\mathrm{x}-\mathrm{y}} \mathrm{Ti}_{\mathrm{y}}\right) \mathrm{O}_{3}$ with temperature at selected frequencies. Usually, in ferroelectric materials, dielectric constant increases with increase in temperature up to a critical temperature, called transition temperature[16]. The anomaly in the temperature profile is associated with the ferroelectric-paraelectric transition. No dielectric anomaly is observed in BFO sample in the experimental temperature range but for BFPTO and BFPZTO samples dielectric anomaly was observed in temperature range of $400^{\circ} \mathrm{C}$ to $450^{\circ} \mathrm{C}$. It indicates that the transition temperature decreases due to $\mathrm{Pb}$, $\mathrm{Zr} / \mathrm{Ti}$ substitution. The temperature corresponding to the dielectric anomaly shifts towards the lower side as $\mathrm{Zr}$ is added to BFPTO sample. This may be due to the lower ferroelectric transition temperature of PZT than that of lead titanate [17].The temperature rate of increase of dielectric constant is more at low frequency. The tan $\delta \sim$ temperature graph is the complementary of $\varepsilon_{\mathrm{r}} \sim$ temperature graph. For all the observed frequency range the loss factor shows a peak at the dielectric anomaly temperature. The peak value of loss factor decreases with increase in frequency. The loss factor in BFPTO compound is very small as compared to that of BFPZTO. But in both the modified BFO compounds, the dielectric loss is observed to be very small as compared to that of pure BFO. At higher temperature, the loss due to leakage current is a major constraint to the material for its device applications. In pellet samples, the high temperature loss is primarily due to domain wall motion, inter-grain spacing and other defects. The decrease in dielectric loss due to substitution of $\mathrm{Pb}, \mathrm{Zr}$ and/or Ti may be attributed to the increase in density of crystal, which produces larger grain boundary resistance.
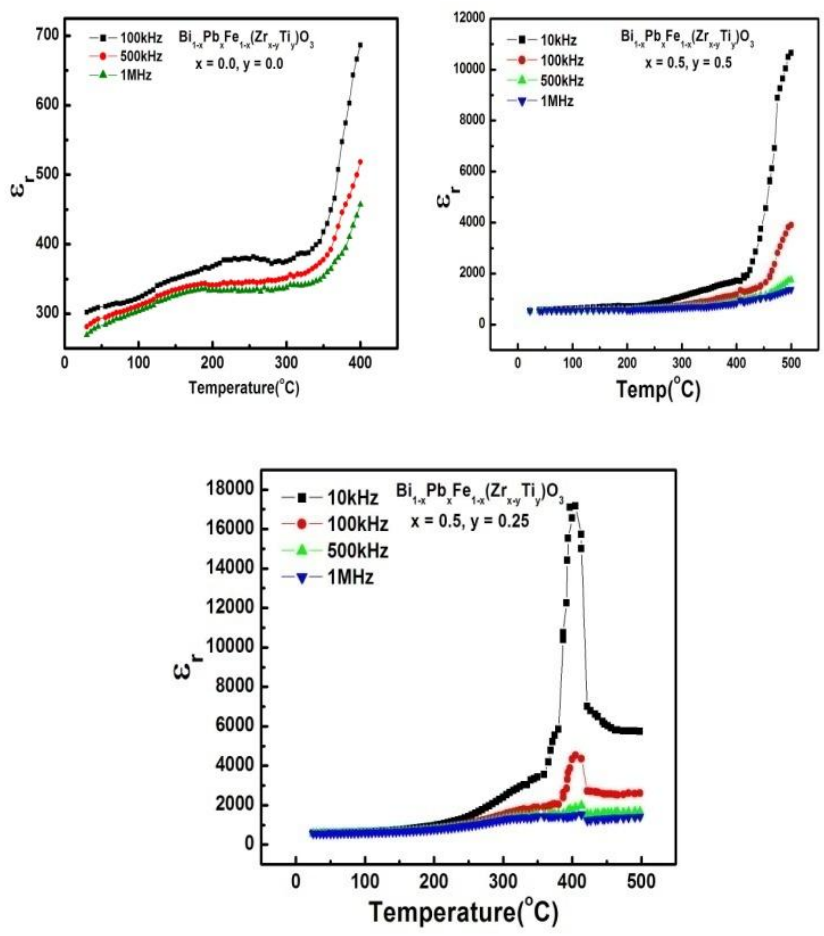

Figure 5: Variation of dielectric constant $\left(\varepsilon_{r}\right)$ of $\mathrm{Bi}_{1-\mathrm{x}} \mathrm{Pb}_{\mathrm{x}} \mathrm{Fe}_{1-\mathrm{x}}\left(\mathrm{Zr}_{\mathrm{x}-\mathrm{y}} \mathrm{Ti}_{\mathrm{y}}\right) \mathrm{O}_{3}$ compounds with Temperature at selected frequencies
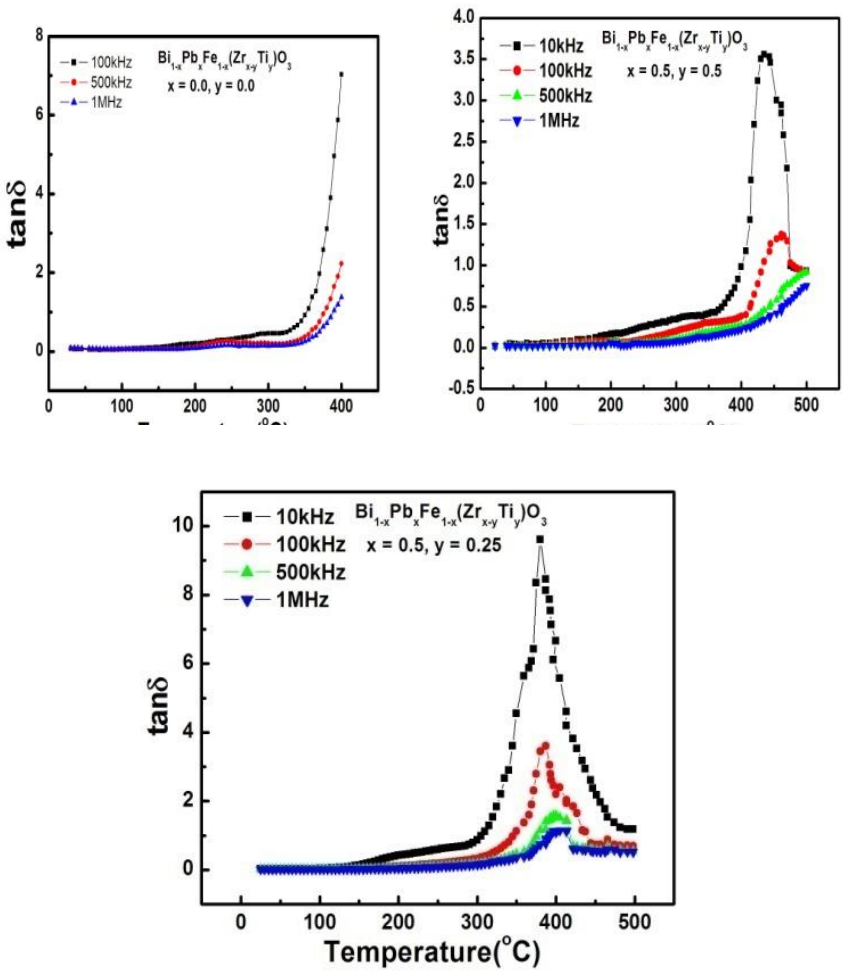

Figure 6(a-c): Variation of dielectric loss $(\tan \delta)$ of $\mathrm{Bi}_{1-\mathrm{x}} \mathrm{Pb}_{\mathrm{x}} \mathrm{Fe}_{1-\mathrm{x}}\left(\mathrm{Zr}_{\mathrm{x}-\mathrm{y}} \mathrm{Ti}_{\mathrm{y}}\right) \mathrm{O}_{3}$ compounds with Temperature at selected Frequencies 
Figure 7(a-c) represents the ferroelectric hysteresis $(\mathrm{P} \sim \mathrm{E})$ loop of the $\mathrm{Bi}_{1-\mathrm{x}} \mathrm{Pb}_{x} \mathrm{Fe}_{1-\mathrm{x}}\left(\mathrm{Zr}_{\mathrm{x}-\mathrm{y}} \mathrm{Ti}_{\mathrm{y}}\right) \mathrm{O}_{3}$ compounds traced at room temperature. It is clearly observed that the saturation polarization of the $\mathrm{Pb}, \mathrm{Ti}$ and/or $\mathrm{Zr}$ modified compounds is significantly larger than that of pure BFO compound, which confirms the enhancement of extent of polarization and polarization stability due to doping. Also the coercive electric fieldis lowered as a result of doping. Thus the ferroelectric behaviors of $\mathrm{BFO}$ get enhanced when its $\mathrm{A}$-site is substituted by $\mathrm{Pb}$ and $\mathrm{B}$-site by $\mathrm{Ti}$ and/or $\mathrm{Zr}$.

(a)

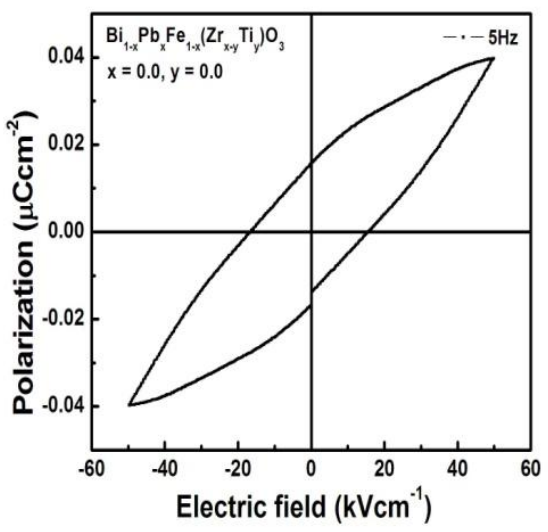

(b)

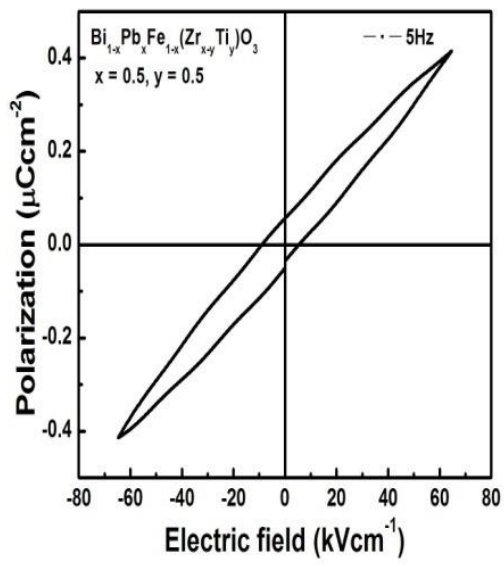

(c)

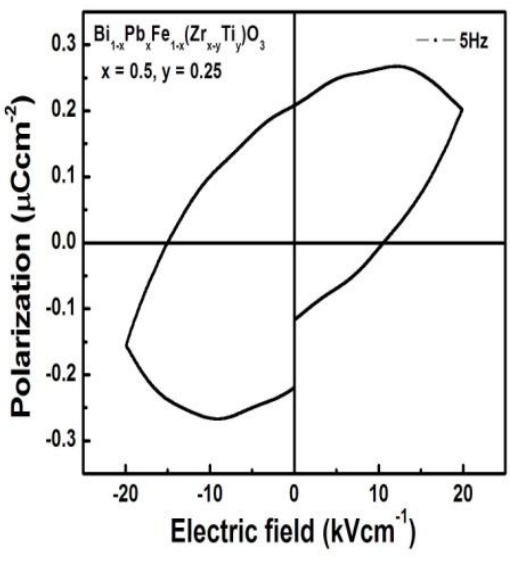

Figure 7(a-c): Ferroelectric hysteresis loop of $\mathrm{Bi}_{1-\mathrm{x}} \mathrm{Pb}_{\mathrm{x}} \mathrm{Fe}_{1-\mathrm{x}}\left(\mathrm{Zr}_{\mathrm{x}-\mathrm{y}} \mathrm{Ti}_{\mathrm{y}}\right) \mathrm{O}_{3}$ compounds

\subsection{Impedance and modulus analysis:}

Complex impedance spectroscopy is a flexible and non-destructive technology to analyze dielectric and electric characteristics of ceramic materials simultaneously over a wide frequency and temperature range [18]. It provides fundamental information about the contribution of grain, grain boundary and electrode to the dielectric parameters of the sample. The structural dependence of electrical characteristics of polycrystalline oxide ceramic samples at various temperatures in a wide perturbed frequency range can also be explored with the help of CIS technique.

Figure 8 (a-c) shows the complex impedance spectra (Cole-Cole) plot of the $\mathrm{Bi}_{1-\mathrm{x}} \mathrm{Pb}_{\mathrm{x}} \mathrm{Fe}_{1-\mathrm{x}}\left(\mathrm{Zr}_{\mathrm{x}-\mathrm{y}} \mathrm{Ti}_{\mathrm{y}}\right) \mathrm{O}_{3}$ compounds with (i) $x=0.0 \& y=0.0$ (ii) $x=0.5 \& y=0.5$ (iii) $x=0.5 \& y=0.25$ at selected temperatures [19]. At lowtemperature, the impedance of the materials is very sensitive to the temperature. The high temperature impedance plot of BFPTO and BFPZTO is characterize by a single semicircular arc with decreasing radius as the temperature increases. This indicates that the bulk resistance decreases with rise in temperature, thus bulk conductivity increases. The impedance spectra of BFO are characterized by two merged depressed semicircles, indicating the contribution of bulk and grain boundary resistance to the impedance of the material. The bulk resistance of BFO also decreases with increase in temperature. Hence each compound possesses NTCR (negative temperature coefficient of resistance) behavior [20]. The transformation of arcs with temperature indicates single relaxation process in the material characterized by a distribution of relaxation times with a mean relaxation time [21]. The depressed semicircular impedance spectra at high temperature suggest that the relaxation in the material is non-Debye type [22]. The existence of a full, partial or no semicircular (observed at low temperature and not presented here) indicates the presence of multiple relaxation process coexists in the studied material, which consists of a number of energy barriers due to point defects appearing during the synthesis. Hence the non- Debye type relaxation in the studied materials may have resulted from dipole interaction, temperature and frequency dependent space charge and ionic polarization and grain boundary sliding. 

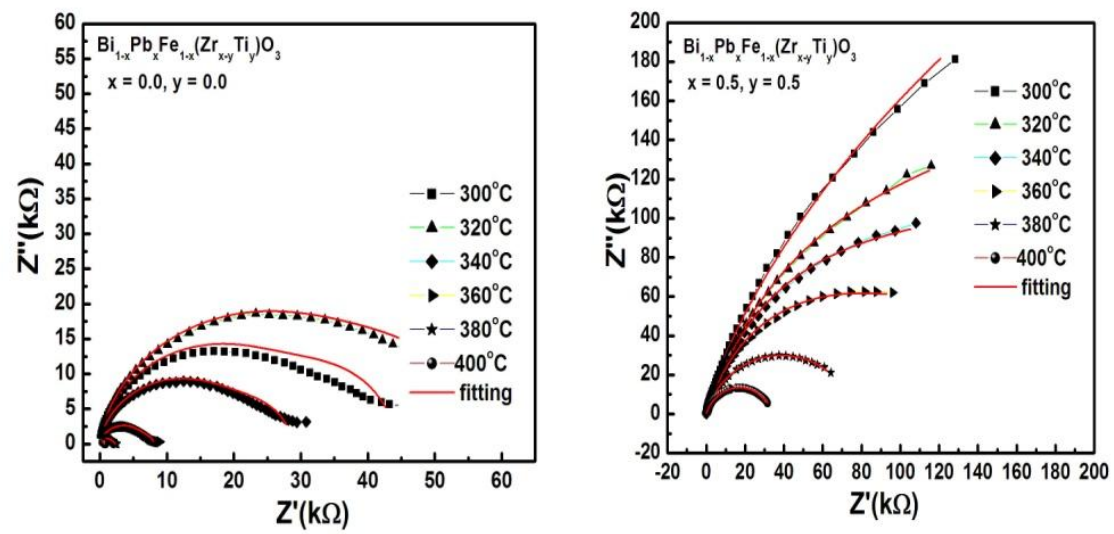

Volume $13 \mathrm{Number} 4$

Figure 8(a-c): Nyqist plots of $\mathrm{Bi}_{1-\mathrm{x}} \mathrm{Pb}_{\mathrm{x}} \mathrm{Fe}_{1-\mathrm{x}}\left(\mathrm{Zr}_{\mathrm{x}-\mathrm{y}} \mathrm{Ti}_{\mathrm{y}}\right) \mathrm{O}_{3}$ compounds at selected high temperatures

Figure 9(a-c) shows the complex modulus spectra of the $\mathrm{Bi}_{1-\mathrm{x}} \mathrm{Pb}_{\mathrm{x}} \mathrm{Fe}_{1-\mathrm{x}}\left(\mathrm{Zr}_{\mathrm{x}-\mathrm{y}} \mathrm{Ti}_{\mathrm{y}}\right) \mathrm{O}_{3}$ compounds; (i) $\mathrm{x}=0.0$ \& $\mathrm{y}=0.0$ (ii) $\mathrm{x}$ $=0.5 \& y=0.5$ (iii) $x=0.5 \& y=0.25$. The modulus spectrum explains the phenomenon related to the bulk and grain boundary capacitance and its contribution to the impedance of the material and relaxation behavior of the charge carriers [23-25]. The real and imaginary parts of electric modulus in terms of $\mathrm{R}$ and $\mathrm{C}$ (for a parallel combination) can be expressed as:

$M^{\prime}=\left(C_{d} / C\right)\left[(\omega R C)^{2} / 1+(\omega R C)^{2}\right]=M\left[\omega^{2} T^{2} / 1+\omega^{2} T^{2}\right]$

$M^{\prime \prime}=\left(C_{d} / C\right)\left[(\omega R C) /(1+\omega R C)^{2}\right]=M\left[\omega t / 1+\omega^{2} r^{2}\right]$

Where $M=\left(C_{0} / C\right), T=R C$ (relaxation time)
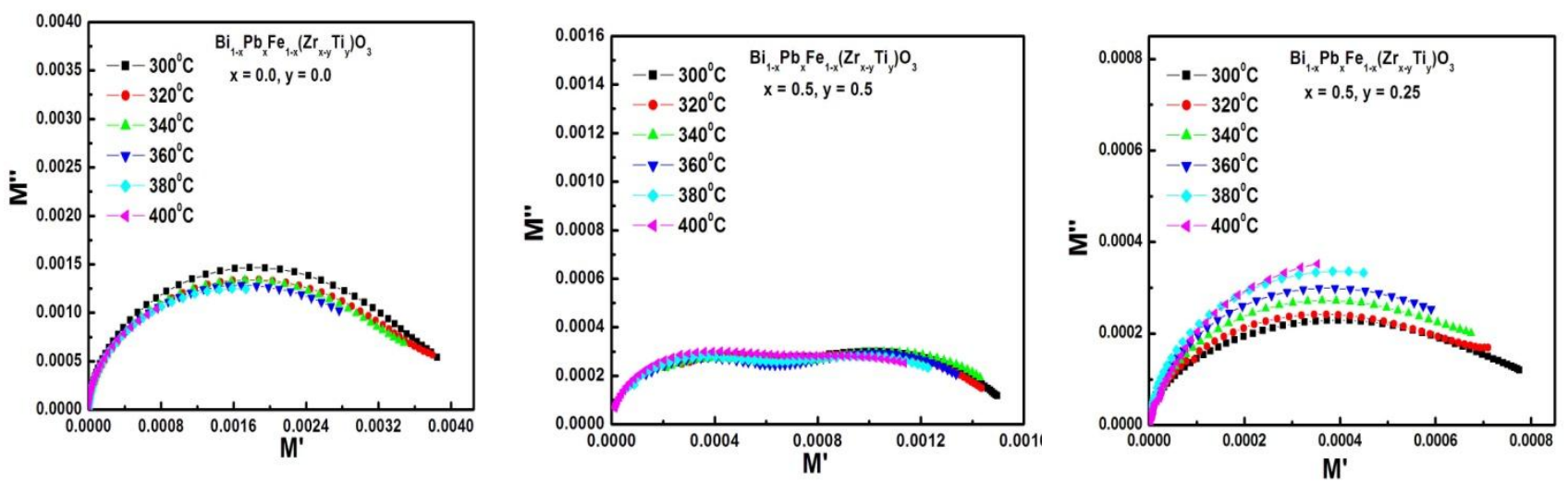

Figure 9(a-c): Complex modulus plots of $\mathrm{Bi}_{1-\mathrm{x}} \mathrm{Pb}_{\mathrm{x}} \mathrm{Fe}_{1-\mathrm{x}}\left(\mathrm{Zr}_{\mathrm{x}-\mathrm{y}} \mathrm{Ti}_{\mathrm{y}}\right) \mathrm{O}_{3}$ compounds at selected high temperatures

The complex modulus plots of BFO and BFPZTO show two resolved semicircular arc at different temperatures. The first one represents the capacitive grain boundary effects in low temperature region and the second one corresponds to the capacitive effect of grains at elevated temperatures [26]. This suggests single relaxation phenomenon in these materials. But two semicircles are clearly seems to be merged in the complex modulus plot of BFPTO compound indicating existence of multiple relaxation in the material [27]. 


\subsection{Ac conductivity analysis $\left(\sigma_{a c}\right)$}

The ac conductivity of the polycrystalline ceramic materials intrinsically depends on its composition, structure, bulk size, distribution of grains, capacitive and resistive effect of grains and/or grain-boundary [28]. The conduction may be due to long range hopping of the charge carriers and/or due to localized transportation accompanied with oxygen vacancies. The ac conductivity of the ceramic compounds under study was calculated by using following equation; $\sigma_{a c}=\omega \epsilon_{r} \epsilon_{o} \tan \delta$

Where, $\epsilon_{r} \epsilon_{o}=$ permittivity of the material, $\tan \delta=$ dielectric loss

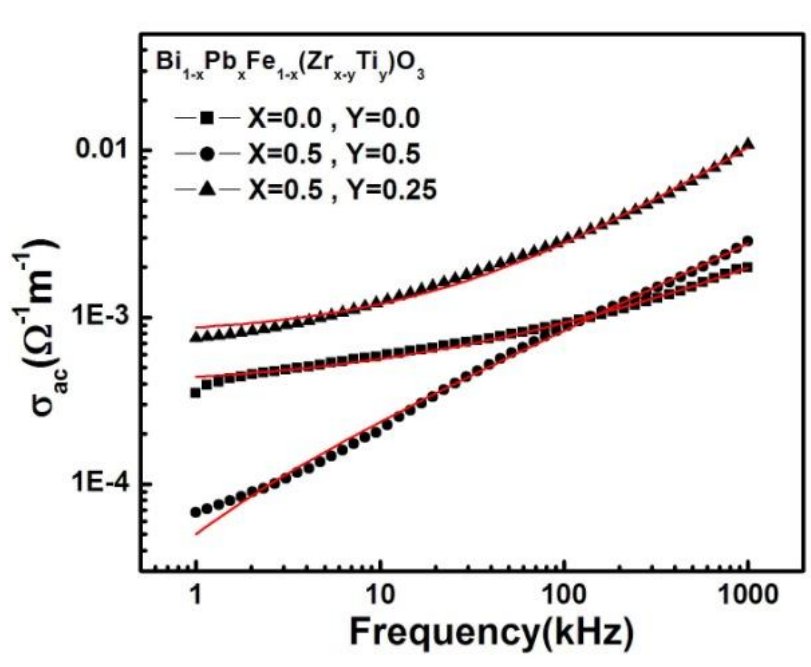

Figure 10: Frequency response of ac conductivity of $\mathrm{Bi}_{1-\mathrm{x}} \mathrm{Pb}_{\mathrm{x}} \mathrm{Fe}_{1-\mathrm{x}}\left(\mathrm{Zr}_{\mathrm{x}-\mathrm{y}} \mathrm{Ti}_{\mathrm{y}}\right) \mathrm{O}_{3}$ compounds at $300^{\circ} \mathrm{C}$
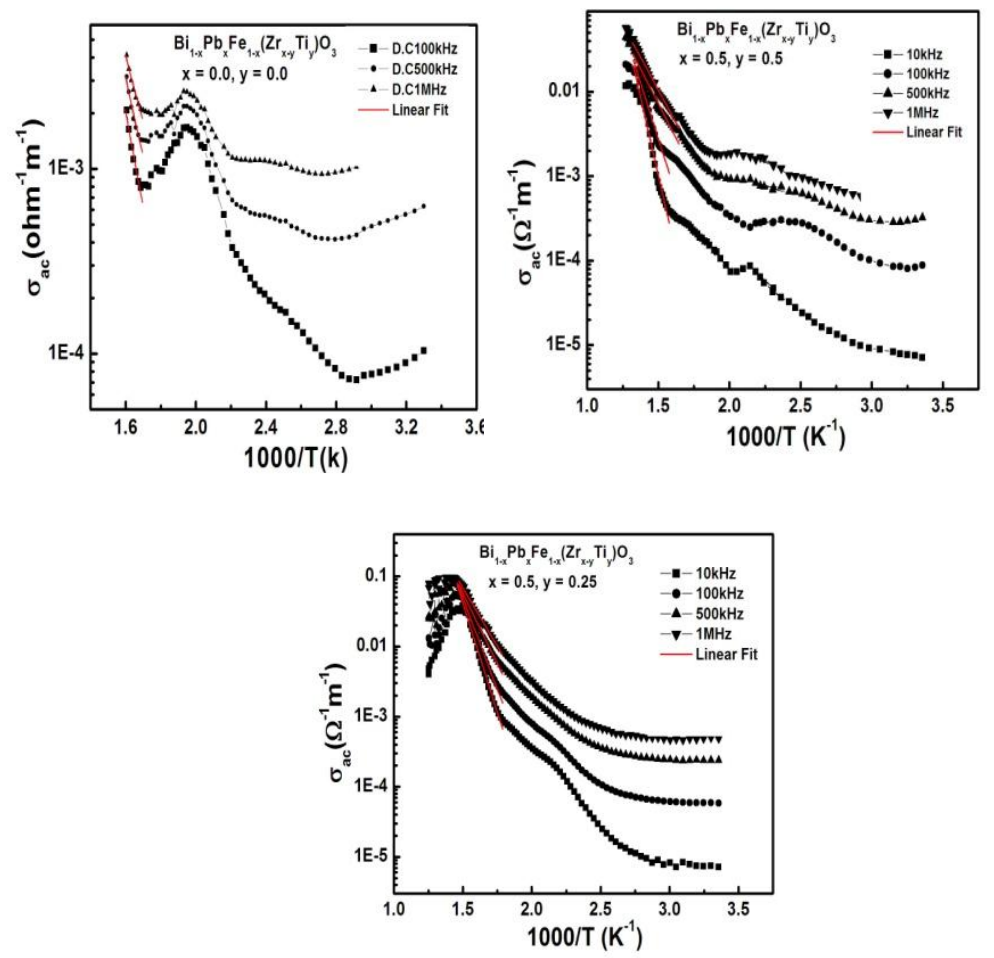

Figure 11(a-c): Arrhenius Plots for $\mathrm{Bi}_{1-\mathrm{x}} \mathrm{Pb}_{\mathrm{x}} \mathrm{Fe}_{1-}$ $x\left(\mathrm{Zr}_{\mathrm{x}-\mathrm{y}} \mathrm{Ti}_{\mathrm{y}}\right) \mathrm{O}_{3}$ compounds at selected frequencies

The comparative study of frequency response of the ac conductivity $\left(\sigma_{a c}\right)$ of the samples of $\mathrm{Bi}_{1-x} \mathrm{~Pb}_{\mathrm{x}} \mathrm{Fe}_{1-\mathrm{x}}\left(\mathrm{Zr}_{\mathrm{x}-\mathrm{y}} \mathrm{Ti}_{\mathrm{y}}\right) \mathrm{O}_{3}$ at temperature $300^{\circ} \mathrm{C}$ is shown in the $\sigma_{a c} \sim$ frequency plot Figure-10. The flattened nature of the plots at lower frequencies suggests that the d.c conduction in the sample dominates the ac conduction.The dispersion of conductivity in the high frequency region is due to the typical RC network. At high frequency, the capacitive reactance of the sample decreases, hence the impedance is reduced, which causes an increase in the ac conductivity of the sample [29-31]. The high conductivity in the material is believed to result from the high defect concentration, and may be due to oxygen octahedral tilt generated because of $\left(\mathrm{Pb}^{2+}\right)$ substitution and end members of BFO and PZT. The large slope at high frequency may be interpreted as the conductivity due to the hopping of the mobile species, which increases with increase in frequency $(\omega)$ and proportional to $\omega^{n}$ according to Jonscher law : $\sigma_{\mathrm{ac}}(\omega)=\sigma_{\mathrm{dc}}+\operatorname{A} \omega^{\mathrm{n}}$, Which indicates that the electrical network $R C$ response is qualitatively similar to the universal dielectic response (UDR) [32]. The frequency exponent $n$ in Jonscher's equation depends on is temperature and material. The value of 
$n \leq 1$, signifies translational motion ofcharge carriers with a sudden hopping, but the value of $n \geq 1$ signifies small localized hopping of the species without leaving their neighborhood [33].

Figure11(a-c) shows the variation of logarithmic value of ac conductivity of $\mathrm{Bi}_{1-x} \mathrm{~Pb}_{x} \mathrm{Fe}_{1-x}\left(\mathrm{Zr}_{x-y} \mathrm{Til}_{y}\right) \mathrm{O}_{3}$ compounds with (i) $x=0.0 \& y=0.0$ (ii) $x=0.5 \& y=0.5$ (iii) $x=0.5 \& y=0.25$ with respect to the inverse of absolute temperature (Arrhenius plots) at selected frequencies $10,100,500$ and $1000 \mathrm{kHz}$. The plots indicate the presence of single relaxation in the materials. In most dielectric materials, conductivity increases with increase in temperature steadily with some anomalies at transition temperature. In all the samples, the value of $\sigma_{\mathrm{ac}}$ increases with increase in frequency in the low-temperature region indicating the dispersive nature of conductivity with frequency. The increase of conductivity with increase in temperature for all frequencies shows that the temperature coefficient of resistivity of the materials is negative i.e., the material exhibit NTCR behavior [34].

Table-2: Comparison of activation energy $E_{a}(\mathrm{eV})$ of $\mathrm{Bi}_{1-\mathrm{x}} \mathrm{Pb}_{\mathrm{x}} \mathrm{Fe}_{1-\mathrm{x}}\left(\mathrm{Zr}_{\mathrm{x}-\mathrm{y}} \mathrm{Ti}_{\mathrm{y}}\right) \mathrm{O}_{3}$ compounds at selected frequencies in high temperature range.

\begin{tabular}{|c|l|l|l|l|}
\hline $\mathrm{x}$ & $\mathrm{y}$ & $100 \mathrm{kHz}$ & $500 \mathrm{kHz}$ & $1 \mathrm{MHz}$ \\
\hline 0.0 & 0.0 & 1.024 & 0.838 & 0.702 \\
\hline 0.5 & 0.5 & 1.054 & 0.649 & 0.616 \\
\hline 0.5 & 0.25 & 1.034 & 0.793 & 0.661 \\
\hline
\end{tabular}

At high temperature, the dispersion in conductivity decreases and all the curves tends to merge. It is also noticed from the plots that curves are merging with increase in the concentration of PZT in the compounds of BPFZTO, which indicates that the conductivity is dominated by charge carriers such as oxygen vacancies. The values of activation energy are found to increase with increase in temperature in all compounds which justify the fact that more energy is required to overcome the fluctuations occurring due to the thermal excitation of charge carriers. This is due to the fact that at low frequencies the overall conductivity is due to the hopping/mobility and transportation of charge carriers over a long distance while at higher frequencies the hopping is localized near the neighboring defect site because the charge carriers have smaller response time to external excitations [35]. Comparison of activation energy $E_{a}(\mathrm{eV})$ of $\mathrm{Bi}_{1-x} \mathrm{~Pb}_{x} \mathrm{Fe}_{1-\mathrm{x}}\left(\mathrm{Zr}_{\mathrm{x}-\mathrm{y}} \mathrm{Ti}_{\mathrm{y}}\right) \mathrm{O}_{3}$ compounds at selected frequencies in high temperature range are presented in Table-2. This indicates that the ac activation energy decreases with increase in frequency in all the studied compounds.

\section{CONCLUSIONS:}

Three polycrystalline samples of $\mathrm{Pb}, \mathrm{Ti}$ and/or $\mathrm{Zr}$ modified bismuth ferrite compounds [i.eBi ${ }_{1-x} \mathrm{~Pb}_{x} \mathrm{Fe}_{1-x}\left(\mathrm{Zr}_{\mathrm{x}-\mathrm{y}} \mathrm{Ti}_{\mathrm{y}}\right) \mathrm{O}_{3}$, with (i) $x=0.0 \& y=0.0$ (ii) $x=0.5 \& y=0.5$ (iii) $x=0.5 \& y=0.25$ ]were prepared by a standard solid-state mixed oxide method. Preliminary structural analysis indicates the existence of rhombohedral phase symmetry (R3c space group) for BFO compound but tetragonal crystal system (with space group $\mathrm{P} 4 \mathrm{~mm}$ ) for the $\mathrm{Pb}$ and $\mathrm{Ti}$ and/or $\mathrm{Zr}$ modifiedBFO compounds. The dielectric constant $\left(\varepsilon_{r}\right)$ is observed to be larger in the modified compounds than that in BFO, and also the dielectric loss decreases significantly in the doped materials. Hence the leakage current in the modified compounds is less than that in BFO. Thus the modified compounds have larger potentiality for device applications. The SEM picture of the studied compounds indicates that the grain size decreases due to doping and the grains are distributed uniformly with low porosity. The $\mathrm{P} \sim \mathrm{E}$ hysteresis loop suggests that the ferroelectric behavior of BFO is enhanced due to the substitution of $\mathrm{Pb}, \mathrm{Ti}$ and/or $\mathrm{Zr}$ on Bi-site and Fe-site of bismuth ferrite (BFO). The frequency dependence of ac conductivity obeys the Jonscher's universal power law for all compositions. Detailed study of electrical conductivity of the materials exhibits its NTCR behavior. 


\section{ACKNOWLEDGMENT:}

The authors are grateful to Professor H.B.K. Sharma of Manipur University, for his kind help for the SEM micrographs and Prof. Ashok Kuma of National Physical Laboratory (CSIR), New Delhi, for his kind help for the PE Loop of Bi $i_{1}$ ${ }_{x} \mathrm{~Pb}_{x} \mathrm{Fe}_{1-x}\left(\mathrm{Zr}_{\mathrm{x}-\mathrm{y}} \mathrm{Ti}_{\mathrm{y}}\right) \mathrm{O}_{3}$ samples.

\section{REFERENCES:}

[1] Nye J. F. 1960 Physical Properties of Crystals, Oxford University Press, Oxford.

[2] Tejuca L. G., Ferro J. L. G. 1993 Properties and Applications of Perovskite-type oxides, Marcel Dekker, Inc.

[3] Mitchell R. H., 2002 Perovskite modern and ancient, Alamaz Press Inc., Thunder Bay.

[4] Smolenski G., Physical Phenomena in Ferroelectrics with Diffused Phase transition, 1970 J. Phys. Soc. Jpn. Suppl., 28, 26-28.

[5] Zhu W,-M., Guo H,-Y., Ye Z.-G., 2008, Structural and Magnetic Characterization of Multiferroic (BiFeO3)1x $\left(\mathrm{PbTiO}_{3}\right)_{x}$ solid solutions, Phy. Rev. B, 78, 014401.

[6] Catalan G. and Scott J. F., 2009 Physics and Applications of Bismuth Ferrite, Adv. Mater, 21, 2463-2485.

[7] Lebeugle D., Coulson D., Forget A. M. Viret, A. M. Bataille and A. Guskasov, 2008 Electric field induced spin flop in $\mathrm{BiFeO} 3$ single crystals at room temperature,Phys. Rev. Lett.100, 227602.

[8] Kubel F., Schmid H., 1990 Structure of ferroelectric and ferroelastic monodomain crystal of the perovskite $\mathrm{BiFeO}_{3}$ Acta Cryst. B, 46, 698.

[9] Teague J. R., Gerson R. and James W. J., 1970 Dielectric hysteresis in single crystal $\mathrm{BiFeO}_{3}$ Solid State Comm. 8, 1073.

[10] Zhu W,-M., Guo H,-Y., Ye Z.-G., 2008 Structural and Magnetic Characterization of Multiferroic (BiFeO3)1x $\left(\mathrm{PbTiO}_{3}\right)_{x}$ solid solutions, Phy. Rev. B, 78, 014401.

[11] Ismailzade G., $1968 \mathrm{X}$-ray Diffraction Study of Phase Transitions in the $\mathrm{BiFeO}_{3}-\mathrm{Pb}\left(\mathrm{Fe}_{0.5} \mathrm{FNd}_{0.5}\right)_{3}$ system, Kristallografiya, 13, [3], 431-434.

[12] Bhide V. G., Deshmukh K. G., Hegde M. S., 1962 Ferroelectric Properties of $\mathrm{PbTiO}_{3}$, Physica : 28, 871 876.

[13] lijima T., Ito S., Matsuda H., Dugnani R.and Fu-Kuo Chang, 2004 Ferroelectric and Piezoelectric Properties of Disk Shape Lead Zirconate Titanate Thick Films, Materials Transactions, 45, [2], 233- 235.

[14] POWDMULT: An interactive Powder Diffraction Data Interpretation and Indexing Program Version 2.1, E. Wu School of Physical Sciences, Flinders University of South Australia, Bradford Park, SA 5042, Australia.

[15] Panda N., Pattanayak S. , et al. 2015 Structural, Dielectric and Electrical Properties of $\mathrm{Bi}_{1-x} \mathrm{~Pb}_{x} \mathrm{Fe}_{1}$. $x\left(\mathrm{Zr}_{0.5} \mathrm{Ti}_{0.5}\right)_{\mathrm{x}} \mathrm{O}_{3}$, J. Electronic Materials, 44, 12.

[16] Gonzalo J. A., Caballero A. C., Moure C., Cox D. E., and Shirane G., 2000 New features of the morphotropic phase boundary in the $\mathrm{Pb}\left(\mathrm{Zr}_{1-\mathrm{x}} \mathrm{Ti}_{\mathrm{x}}\right) \mathrm{O}_{3}$ system, Ferroelectrics, 237, [1-4], 541-548. 
[17] Woodward D.I., Knudsen J., and Reaney I. M., 2005 Review of crystal and domain structures in the PbZrxTi1-xO3 solid solution, Physical Review B: 72, [10], 104110.

[18] Impedance Spectroscopy, J. Ross McDonald, Willey, New York (1987).

[19] Gavriliuk A. G., Struzhkin, Lyubutin I. S., and Troyan I. A., 2007 Equation of State and Structural Transition at High Hydrostatic Pressure in the $\mathrm{BiFeO}_{3}$ Crystal, JETP Lett., 86, [3], 197.

[20] Wu X. J., Wu C. L., Wei W., Peng B., Huang W., and Goodenough J. B., 2006 Tunable Synthesis of Bismuth Ferrites with Various Morphologies Adv. Mater. 18, 2145.

[21] Nalwa K. S., Garg A., Upadhyaya A., 2008 Effect of samarium doping on the properties of solid-state synthesized multiferroic bismuth ferrite, Matter Lett. 62, 878-881.

[22] Jonscher A. K, 1980 Non-Debye dielectric tresponses J. Phy. D: Apll. Phys. 13, L89-93.

[23] Gerhardt R., 1994 Impedance and dielectric spectroscopy revisited: Disntinguishing localized relaxation from long range conductivity,J. Phys. Chem. Of Solids, 55, 1491-1506

[24] Uchino K., 1994 Relaxor ferroelectric devices, Ferroelectrics, 151, 321-330.

[25] Sinclair D. C., West A. R., 1989 Impedance and Modulus spectroscopy of semiconducting $\mathrm{BaTiO}_{3}$ showing positive temperature coefficient of resistance J. Appl. Phys. 66, 3850-3856.

[26] Nowick A. S., Lim B. S., 2001 Electrical relaxations: simple vs. complex ionic systems, Physical Rev. B: 63, [1-7], 1841145.

[27] Dash S., Padhee R., Das P. R., Choudhary R.N.P., 2013 Dielectric and impedance spectroscopy of (Bi $i_{0.5}$ $\left.\mathrm{Li}_{0.5}\right)\left(\mathrm{Fe}_{0.5} \mathrm{Nb}_{0.5}\right) \mathrm{O}_{3}$ multiferroics, Phase Transitions, 10, 01411594.

[28] Simmons J. G., Nadkarni G. S., Lancaster M.C., 1970 Alternating Current Electrical Properties of Highly Doped Insulating Films, J. Appl. Phys. 41, 538-544.

[29] Barranco A., Abreu Y., Noda R. L., 2008 Dielectric relaxation and conductivity behavior in modified lead titanate ferroelectric ceramics, J. Phys.: Condens. Matter. 20, 5052081-1-10.

[30] Ahmed M.A., Mansour S. F., El-Dek S. I., Abu-Abdeen M., 2014 Conduction and magnetization improvement of $\mathrm{BiFeO}_{3}$ multiferroic nanoparticles by $\mathrm{Ag}^{+}$doping, Materials Research Bulletin, 49, 352359.

[31] Ngai K. L., White C. T., 1979 Frequency dependence of dielectric loss in condensed matter Phys. Rev. B, 20, 2475-2486.

[32] Jonscher A. K., 1977 The universal dielectric response, Nature, 267, 673-682.

[33] Gerhardt R., 1994 Impedance and dielectric spectroscopy revisited: distinguishing localized relaxation from long range conductivity, J. Phys. Chem. Solids, 55, 1491-1506.

[34] Bharti R., Singh R., Wankly B. M., 1981 On electrical transport in $\mathrm{COWO}_{4}$ single crystals, J. Mat. Sci. 16, 775-779.

[35] Funke K., Prog. 1993 On electrical transport in $\mathrm{COWO}_{4}$ single crystals, Solid State Chem, 22, 111-195. 